\title{
Exploring Instructors' Verbal Aggressiveness and Students' Personal Orientations and Reasons of Discipline in Physical Education Class
}

\author{
Alexandra Bekiari, Ioanna Tsiana \\ Faculty of Physical Education and Sports Science, University of Thessaly, Thessaly, Greece \\ Email: sandrab@pe.uth.gr
}

Received 5 June 2016; accepted 1 August 2016; published 4 August 2016

Copyright (C) 2016 by authors and Scientific Research Publishing Inc.

This work is licensed under the Creative Commons Attribution International License (CC BY).

http://creativecommons.org/licenses/by/4.0/

c) (i) Open Access

\section{Abstract}

In this study we examined associations among physical education instructors' verbal aggressiveness as perceived by students and students' task and ego orientations and reasons for discipline. The sample consisted of 283 Greek adolescent students (124 males, 159 females) aged 10 - 14 years old $(M=12.6, S D=.94)$ from primary and secondary schools who completed three types of questionnaires during physical education classes. The results supported the internal consistency of the instruments. MANOVA's findings supported that there is a significant dependence between school classes on the factors of each questionnaire. Specifically, the $2^{\text {nd }}$ grade of secondary school proved to have the lower score on verbal aggressiveness, the $2^{\text {nd }}$ grade of secondary school the higher score on ego-orientation, the $1^{\text {st }}$ grade of secondary school the higher score on external reasons of discipline and the $5^{\text {th }}$ grade of primary school the lower score on caring reasons. Correlational analysis indicated that perceived instructors' verbal aggressiveness was positively related to students' ego orientation, external reasons, introjected reasons, no reasons, and self-responsibility reasons for discipline. Significant negative correlations were noted for instructors' verbal aggression with students' task orientation, intrinsic reasons and caring reasons for discipline. The results of regression analysis revealed that perceived instructors' verbal aggressiveness could significantly predict the variables of students' personal orientations and external reasons, intrinsic reasons and self-responsibility reasons for discipline. Distinct types of disciplined students are also proposed: 1) the "obedient" and 2) "altruist". The findings and implications of the contribution of instructors' verbal aggressive behavior to the students' personal orientations and reasons for discipline are further discussed as well as future research suggestions.

\section{Keywords}

Verbal Aggressiveness, Task and Ego Orientations, Discipline 


\section{Introduction}

\subsection{Verbal Aggressiveness}

Verbal aggression is defined as the attack a person's self-concept of the other in order to cause psychological pain as attack on character, competence, physical appearance, teasing, ridicule, threats, swearing, and profanity (Infante \& Rancer, 1996). In all types of relationships, research consistently shows that verbal aggressiveness leads to negative outcomes (Anderson \& Martin, 1995; Bekiari, 2012, 2014; Bekiari \& Hasanagas, 2015, 2016; Bekiari \& Manoli, 2016; Bekiari \& Sakellariou, 2002; Hasanagas \& Bekiari, 2015; Infante, Myers, \& Buerkel, 1994; Infante \& Rancer, 1996; Manoli \& Bekiari, 2015). Concerning education system, it has been supported that verbal aggressiveness is a demotivating force in the classroom (Gorham \& Christophel, 1992) that is negatively related to social, task and physicalattraction (Syrmpas \& Bekiari, 2015), perceptions of immediacy (Martin, Weber, \& Burant, 1997; Rocca \& McCroskey, 1999), student affect toward the course content, the teacher and the recommended course behaviors (Bekiari, 2012; Myers \& Knox, 1999; Wrench \& Richmond, 2004), motivation climate and satisfaction (Bekiari, 2014; Bekiari, Kokaridas, \& Sakellariou, 2005, 2006; Bekiari, Perkos, \& Gerodimos, 2015; Bekiari \& Syrmpas, 2015; Claus, Chory, \& Malachowski, 2011; Manoli \& Bekiari, 2015; Myers, Edwards, Wahl, \& Martin, 2007; Myers \& Rocca, 2001; Schrodt, 2003), student prosocial fair play (Hassandra, Bekiari \& Sakellariou, 2007) and behavior, thinking, motivation (Bekiari \& Hasanagas, 2015; Mazer \& Stowe, 2016; Richmond \& Gorham, 1992). Additionally, students consider teachers verbally aggressive as less reliable than teachers avoid unconstructive communication in the classroom (Bekiari, Koustelios, \& Sakellariou, 2000; Edwards \& Myers, 2007; Mazer \& Stowe, 2016; Schrodt, 2003).

Moreover, students who consider that their physical education instructors are verbally aggressive present a tendency to learning loss (Bekiari \& Sakellariou, 2002) adopting a similar aggressive behavior (Bekiari, Kokaridas, \& Sakellariou, 2005). In a similar context, it has been supported that instructors' verbal aggressiveness has a negative effect on the students' satisfaction, intrinsic motivation factors (such enjoyment and interest, effort/ importance and competence) and discipline factors related to intrinsic and caring reasons (Bekiari, Kokaridas, \& Sakellariou, 2006). Also, Bekiari (2012) found a negative relationship between perceived instructors' verbal aggressiveness and students' affective learning and satisfaction in physical education context. Furthermore, verbally aggressive coaches are likely to be considered as less credible and they probably make athletes feel less motivated (Mazer, Barnes, Grevious, \& Boger, 2013). Moreover, researchers mainly examined the relationship between athletes' aggressiveness and the type of sport (contact or non-contact) (Bredemeier, Weiss, Shields, \& Cooper, 1986; Huang, Cherek, \& Lane, 1999; Lemieux, McKelvie, \& Stout, 2002). Additionally, Bekiari, Digelidis and Sakellariou (2006) argued that athletes who participated in a noncontact sport perceived their coaches as emitting less verbal aggressiveness compared to athletes participating in a high-contact sport. Moreover, male volleyball players rated somatic anxiety higher and were more affected by coaches' verbal aggressiveness than female volleyball players (Bekiari, Patsiaouras, Kokaridas, \& Sakellariou, 2006).

\subsection{Personal Orientations}

The concepts of goal orientation and motivation are referred generally to the way with which each person conceives his ability, defines success and prompts himself to achieve his objectives. Related researches in this field were based on the perception that the individual's achievement targets are determined by whatever the individual considers important and desirable (Dweck \& Leggett, 1988; Nicholls, 1984, 1989; Duda, 1989; Duda \& Nicholls, 1992). The better comprehension of motivation however, requires that the target of behavior should be recognized. According to the theory of Nicholls (1989), inter-personal differences exist in the way with which the people perceive their ability and define success. Thus, in environments of achievement such as the school and sports, two different objectives independent with each other are revealed, the objective of task and ego reinforcement (Duda \& Nicholls, 1992; Li, Harmer et al., 1998; Nicholls, 1989; Williams \& Gill, 1995). Individuals, who are task-orientated conceive success and judge their ability on the basis of their own efforts and personal improvement. On the contrary, individuals who are ego-oriented compare themselves with others or with certain norms in order to decide how good they are. For them, success means the surpassing of others and the demonstration of a high level of abilities.

Treasure and Roberts (1995) argues that when children realize that the course of physical education is directed toward learning, they adopt targets that concern their personal improvement and demonstrate higher mo- 
tivation. So, they participate more actively and have more fun, because they do not worry about their errors or they probably know that when somebody wants to learn it is natural to make mistakes. After all, they all accept that everyone can accomplish his/her goals through practice. On the contrary, in the case of children realizing that the physical education course is directed toward performance, their feeling of success depends on their perception of how good they are compared to others. As a consequence, the errors become sources of stress and the children tend to avoid their participation in physical education classes, especially when they believe that they do not demonstrate the skills to accomplish a task.

It is supported that children with high task orientation demonstrate higher and more constant in time motivation, whereas children directed toward "ego" demonstrate a low or moderate perception for their athletic abilities (Fox, Goudas, Biddle, Duda, \& Armstrong, 1994; Kokaridas, Bekiari, \& Sakellariou, 2005). Research of Linnenbrink and Pintrich (2002) noted that people who are task-oriented believe that slow progress but not meeting expectations is a good opportunity to improve more, while the people who are ego-oriented thought that these problems are an indication of the low competence in relation to others. Furthermore, the instructors' task-orientation associated with students' reports that teachers actively supported the formulation of questions and seeking help (Butler \& Shibaz, 2008; Shim, Sho, \& Cassady, 2013).

The achievement goal framework in terms of task-ego and approach-avoidance dimensions has also been intensively discussed, exploring the possible role of gender, athlete status and psychological parameters (Wang, Biddle, \& Elliot, 2007). Interesting profiles have also been suggested concerning goal orientation, motivation climate and relationship perceptions in young athletes (Smith, Balaguer, \& Duda, 2006). The high perceived sport ability group was featured by an engagement of task-based motivation to enjoyment. In this concept, the relevance of effort, personal development and improvement was pointed out. Task orientation and enjoyment in physical education are emphasized as salient factors inhibiting decline in physical activity (Yli-Piipari, Barkoukis, Jaakkola, \& Liukkonen, 2013). Goal orientations seem to remain independent from the course of the season, as late season task orientation appears to depend on early season and coach task orientation (McPherson, 2015).

Task-based motivation constitutes a predictor of enjoyment in physical education through perceived physical competence and intrinsic motivation. This supported previous findings (Vallerand, Brière, Blanchard, \& Provencher, 1997), involving self-determination and the achievement goal theory and excluding ego-involving climate as rather irrelevant factor (Gråstén, Jaakkola, Liukkonen, Watt, \& Yli-Piipari, 2012).

\subsection{Reasons for Discipline}

Acceptable behavior and discipline is an issue of concern for the educational community (Bekiari \& Hasanagas, 2016) as learning takes place in a well-organized and peaceful atmosphere (Good \& Grouws, 1977; Evertson, Anderson, Anderson, \& Brophy, 1980). Placer and Dodds (1988) argued that a well-disciplined class is one of the most important indices of successful teaching. Hellison (1985) developed strategies to help students take responsibility for their own behaviour and to increase their self-determination. It was proposed a model-an active inclusion of an undisciplined student in class through a series of steps-levels (from 0 to 4 ). Level 0 is characterized as a level of irresponsibility, where the student behaves antisocially and impedes the smooth functioning of both the classroom and the school. With the right assistance, the student can go to level 1, the level of participation, where the student is uninvolved in the classroom, but without harassing his classmates. Then, there is an effort to get to level 2, the level of self-control, where the student participates in class and controls himself, his feelings and reactions. Then the student passes to a higher level 3 of responsibility in which there is self-control and will participate without the direct supervision of a physical education teacher. The goal of this model is for the student to be found on level 4. There, there is care for others, the highest level of responsibility. At this level, the student not only controls himself but he actively participates without the presence of the teacher and cares, helps and offers to others Hellison (1985). Similarly, Deci and Ryan (1985a, 1985b) in their self-determination theory identified self-responsibility and caring reasons along with external, introjected, intrinsic and no reasons as the six internally consistent factors that describe the reasons for being disciplined. Moreover, Giannoudis, Digelidis and Papaioannou (2009) who examined the perceived behavior of physical education teachers to students designated disciplined-undisciplined, in the context of perceived motivational climate. The results showed that the disciplined students, compared unruly adopted a more personal orientation in learning and personal improvement, entertained and disciplined more, they had higher perceived athletic ability and were adopting more self-determined reasons for discipline in class (internal, self-responsibility, caring reasons). 


\section{The Present Study}

From the above, it is obvious that the concepts of verbal aggressiveness, personal orientations and discipline reasons have been sufficiently examined. However, students' personal orientations and discipline reasons during physical education lessons has not yet being linked with verbal aggressiveness of physical education instructors as perceived by students. This study intended to examine the relations among perceived instructors' verbal aggressiveness and students' personal orientations and reasons for discipline during physical education lessons.

In particular, this study intends to answer the following research questions:

- Are there significant differences noted between the sexes and classes regarding verbal aggressiveness, personal orientations and discipline reasons?

- Is there a positive or negative relationship between instructors’ verbal aggressiveness as perceived by students with students' self-reports of personal orientations and their perceptions of reasons for discipline in physical education classes?

- To what extent the perceived instructors' verbal aggressiveness could be a significant predictor of the students' personal orientations and discipline reasons?

- Can a students' typology regarding parameters of verbal aggressiveness perception, orientation and discipline be extracted?

In the light of the findings, useful conclusions is expected to be drawn regarding the relation of instructors' verbal aggression as perceived by students with personal orientations and reasons for being disciplined.

\section{Method}

\subsection{Participants and Procedures}

The sample of the study consisted of 283 students (124 males, 159 females) aged 10 - 14 years old $(M=12.6$, $S D=.94)$ in four cities of central Greece and Athens. All the participants were between the $5^{\text {th }}$ and $6^{\text {th }}$ grade of public primary schools and between the $1^{\text {st }}$ and $2^{\text {nd }}$ grade of public secondary schools and belonged to different socio-economic status. All students completed questionnaires referring to the instructors' verbal aggressiveness and students' personal orientations and discipline reasons, during their physical education lessons, in winter 2015. The completion of questionnaires lasted for 20 - 30 minutes approximately and flowed freely. The anonymity of the participants was ensured and student participation in the process was voluntary in order to obtain sincere answers. The study was conducted in accordance with the best practice rules and research ethics.

\subsection{Instruments}

Verbal aggressiveness. The Greek version (Bekiari \& Digelidis, 2015), which was used to assess physical education teacher verbal aggressiveness, relied on the theoretical framework and the Verbal Aggressiveness Questionnaire (20 items) developed by Infante and Wigley (1986). Preliminary examination (Bekiari \& Digelidis, 2015) supported the psychometric properties of the instrument. In particular, confirmatory factor analysis indicated satisfactory fit indices (confirmatory factor analysis: .97, SRMR: .02), and internal consistency of the scale $(\alpha=.96)$. The scale consisted of eight items (e.g., "the teacher insults students," "the teacher makes negative judgments of students' ability”). Participants were asked to respond on a 5-point Likert-type scale ranging from 1: Strongly disagree to 5: Strongly agree.

Personal orientations. The Task and Ego Orientation questionnaire (Duda, 1989), adapted in Greek population (Papaioannou \& Macdonald, 1993; Papaioannou \& Theodorakis, 1996), was used to assess students’ task and ego orientation. The scale consisted of two factors ("task" and "ego" orientation) and includes a total of 13 questions. Specifically, it is consisted of 7 questions describingtask orientation (e.g. I learn a new exercise trying hard) and 6 questions describing the ego orientation (e.g. I am the only one who can do the exercise). Participants were asked to respond on a 5 point Likert scale (from $1=$ never to $5=$ often).

Reasons for discipline. The Greek version (Papaioannou, 1998), which based on the self-determination theory of Deci and Ryan (1985a, 1985b), was used to assess students’ perceptions of reasons for discipline. The scale consisted of 26 items and six factors: external reasons (4 questions), introjected reasons (3 questions), intrinsic reasons (8 questions), no reasons (3 questions), self-responsibility reasons (4 questions), and caring reasons (4 questions) for being disciplined. Following the stem "When I am disciplined in PE class, it is because..." responses to the items were indicated on a 5-point Likert-type scale, from $1=$ strongly disagree to 5 = strongly agree. 


\subsection{Data Analysis}

Data analysis included the use of the Statistical Package for Social Sciences (SPSS 21.0). Cronbach's $\alpha$ reliability analysis was used to examine the internal consistency of the factors of each questionnaire. Differences in students' perceptions about the verbal aggressiveness, personal orientations and discipline reasons respectively with the gender and class, were examined by performing a two-way MANOVA analysis. The Pearson correlation coefficient was used to measure the correlation between the subscales of the questionnaires.Moreover, regression analysis was conducted in order to explore the extent to which the perceived instructors' verbal aggressiveness could be a significant predictor of the students' personal orientations and discipline reasons. The level of statistical significance was set at 05 .

Finally, a students' typology regarding parameters of verbal aggressiveness perception, orientation and discipline will be formulated using principal component analysis.

\section{Results}

Cronbach's $\alpha$ reliability analysis for the Verbal Aggressiveness Scale (Bekiari \& Digelidis, 2015) was .92. The factors of task orientation $(\alpha=.89)$ and ego-orientation $(\alpha=.91)$ for the Task and Ego Orientation Questionnaire (Duda, 1989) showed a high level of reliability. The factors of external reasons $(\alpha=.88)$, introjected reasons ( $\alpha$ $=.89$ ), intrinsic reasons $(\alpha=.87)$, no reasons ( $\alpha=.85$ ), self-responsibility reasons $(\alpha=.79)$, and caring reasons $(\alpha=.81$ ), for the Reasons of Discipline Scale (Papaioannou, 1998) showed a high degree of reliability.

Moreover, two-way MANOVA was performed to examine differences in verbal aggressiveness, personal orientations and discipline reasons between gender and school class $\left(5^{\text {th }}-6^{\text {th }}\right.$ class of primary school and $1^{\text {st }}-2^{\text {nd }}$ class of secondary school). The findings showed statistically significant multivariate effect on gender (Wilk's $\lambda$ $=.918, \mathrm{~F}[9,268]=2.06, p<.05)$ and on school class(Wilk's $\lambda=.811, \mathrm{~F}[9,268]=1.96, p<.01)$, but no interaction between gender and school class was detected (Wilk's $\lambda=.917, \mathrm{~F}[9,268]=.69, p=.921$ ). The examination of the univariate effects revealed no significant effect of gender on verbal aggressiveness, personal orientations and discipline reasons, but revealed significant effect of school class on verbal aggressiveness $(F[3,273]=2.96$, $p<.05)$, on ego-orientation $(\mathrm{F}[3,273]=4.27, p<.05$, on intrinsic reasons $(\mathrm{F}[3,273]=3.74, p<.05)$ and on caring reasons $(F[3,273]=3.76, p \leq .05)$. An examination of the mean scores indicated that the $2^{\text {nd }}$ class of secondary school $(\mathrm{MO}=3.05, \mathrm{SD}=1.24)$ proved to have the lower score in verbal aggressiveness, the $2^{\text {nd }}$ class of secondary school $(\mathrm{MO}=3.03, \mathrm{SD}=1.28)$ the higher score in ego-orientation, the $1^{\text {st }}$ class of secondary school $(\mathrm{MO}=2.86, \mathrm{SD}=1.31)$ the higher score in external reasons of discipline and the $5^{\text {th }}$ class of primary school $(\mathrm{MO}=2.24, \mathrm{SD}=1.13)$ the lower score in caring reasons.

In addition, a correlation analysis was conducted, the results of which are presented in "Table 1". As it can be seen, there was a negative significant relationship between instructors' verbal aggressiveness and task orientation $(r=-.83)$, intrinsic reasons $(r=-.49)$ and caring reasons for discipline $(r=-.86)$. Moreover, there was a positive significant relationship between instructors' verbal aggressiveness and ego orientation $(r=.89)$, external reasons $(r=.74)$, indrojected reasons $(r=.35)$, no reasons $(r=.46)$ and self-responsibility reasons for discipline $(\mathrm{r}=.50)$.

Table 1. Correlations between variables.

\begin{tabular}{|c|c|c|c|c|c|c|c|c|c|}
\hline Factors & 1 & 2 & 3 & 4 & 5 & 6 & 7 & 8 & 9 \\
\hline Verbal aggressiveness & - & & & & & & & & \\
\hline Task orientation & $-.832^{* *}$ & - & & & & & & & \\
\hline Ego orientation & $.889^{* *}$ & $-.837^{* *}$ & - & & & & & & \\
\hline External reasons & $.737^{* *}$ & $.658^{* *}$ & $.680^{* *}$ & - & & & & & \\
\hline Introjected reasons & $.354^{* *}$ & $.233^{* *}$ & $.311^{* *}$ & $.457^{* *}$ & - & & & & \\
\hline Intrinsic reasons & $-.485^{* *}$ & $-.386^{* *}$ & $-.425^{* *}$ & $-.500^{* *}$ & $-.680^{* *}$ & - & & & \\
\hline No reasons & $.460^{* *}$ & $.389^{* *}$ & $.413^{* *}$ & $.477^{* *}$ & $.660^{* *}$ & $-.885^{* *}$ & - & & \\
\hline Self-responsibility & $.502^{* *}$ & $.405^{* *}$ & $.391^{* *}$ & $.444^{* *}$ & $.343^{* *}$ & $-.199^{* *}$ & $.300^{* *}$ & - & \\
\hline Caring reasons & $-.465^{* *}$ & $-.391^{* *}$ & $-.438^{* *}$ & $-.537^{* *}$ & $-.705^{* *}$ & $.906^{* *}$ & $-.878^{* *}$ & $-.194^{* *}$ & - \\
\hline
\end{tabular}

${ }^{*} p<.05, \stackrel{* *}{p}<.001$. 
Moreover, linear regression analyses were conducted to examine the extent to which students' personal orientations and reasons for discipline could be predicted from the ratings of instructors' verbal aggressiveness. The results indicated that perceived instructor verbal aggressiveness could predict significant variance in personal orientations $\left(\mathrm{F}_{(2,280)}=623.16, p<.001\right)$ with an $\mathrm{R}_{2}$ of $81.7 \%$. Perceived verbal aggressiveness explained $2.6 \%$ of the variance in students' task-orientation $(\beta=-.30, \mathrm{t}=-6.25, p<.001)$ and $12.4 \%$ of the variance in students' ego-orientation $(\beta=.58, \mathrm{t}=13.76, p<.001)$. Another linear regression analysis was conducted to predict student discipline reasons based on teacher verbal aggressiveness. The results indicated that perceived instructor verbal aggressiveness could predict significant variance in reasons for discipline $\left(\mathrm{F}_{(6,276)}=74.17, p\right.$ $<.001$ ) with an $\mathrm{R}_{2}$ of $61.7 \%$. Verbal aggressiveness explained $19.2 \%$ of the variance in students' external reasons $(\beta=.55, \mathrm{t}=11.76, p<.001), 1.3 \%$ of the variance in students' introjected reasons $(\beta=-.15, \mathrm{t}=-3.03, p$ $<.05), 1.6 \%$ of the variance in students' intrinsic reasons ( $\beta=-.31$, $\mathrm{t}=-3.36, p<.001)$ and $4.5 \%$ of the variance in students' self-responsibility reasons $(\beta=.21, \mathrm{t}=5.68, p<.001)$. The results of the regression analyses are presented in “Table 2".

Moreover, in the "Table 3", two types may be distinguished, according to the sources of discipline. The "obedient" is a student who is extensively disciplined due to a wide variety of discipline factors (external and internal ones as well as responsibility). Simultaneously, such a disciplined student is targeted for verbal aggressiveness by the instructors and oriented to learning (task). The "altruist" appears not to be very different. He feels also verbally assaulted by the instructors and patiently interested in learning.

\section{Discussion}

The aim of this study was threefold: 1 ) to explore the relationship between perceived instructors' verbal aggressiveness and students' personal orientations and reasons for discipline, 2) to investigate the influence of instructor verbal aggressiveness on student personal orientations and reasons for discipline and 3) to propose students' typology. The results of the study indicated that perceived instructors' verbal aggressiveness was positively related to students' ego orientation, external reasons, introjected reasons, no reasons, and self-responsibility reasons for discipline, but was negatively related to students' task orientation, intrinsic reasons and caring reasons for discipline. Moreover, perceived instructors' verbal aggressiveness could significantly predict the variables of students' personal orientations and external reasons, intrinsic reasons and self-responsibility reasons for discipline. Distinct types of disciplined students are also proposed: the "obedient" and "altruist". Furthermore, the $2^{\text {nd }}$

Table 2. Regression analysis results according to verbal aggressiveness.

\begin{tabular}{|c|c|c|c|c|c|}
\hline & $\mathrm{B}$ & $95 \%$ CI B & SE & $\mathrm{b}$ & $\mathrm{T}$ \\
\hline Task-orientation & -.29 & $-.39,-.21$ & .05 & -.30 & $-6.25^{* *}$ \\
\hline Ego-orientation & .64 & $.50, .66$ & .04 & .58 & $13.76^{* *}$ \\
\hline External reasons & .58 & $.46, .64$ & .05 & .55 & $11.76^{* *}$ \\
\hline Introjected reasons & -.17 & $-.25,-.05$ & .05 & -.15 & $-3.03^{*}$ \\
\hline Intrinsic reasons & -.33 & $-.49,-.13$ & .09 & -.31 & $-3.36^{* *}$ \\
\hline Self-responsibility & .26 & $.14, .29$ & .04 & .21 & $5.68^{* *}$ \\
\hline
\end{tabular}

${ }^{*} p<.05,{ }^{* *} p<.001$.

Table 3. Mixed typology.

\begin{tabular}{|c|c|c|}
\hline & \multicolumn{2}{|c|}{ Component } \\
\hline & The obedient & The altruist \\
\hline External reasons & .835 & .129 \\
\hline Introjected reasons & .646 & -.572 \\
\hline Intrinsic reasons & -.748 & .566 \\
\hline Self-responsibility reasons & .541 & .264 \\
\hline Caring others reasons & -.757 & .574 \\
\hline Verbal aggressiveness & .884 & .351 \\
\hline Task orientation & .802 & .434 \\
\hline
\end{tabular}

Extraction Method: Principal Component Analysis. a. 2 components extracted. 
grade of secondary school proved to have the lower score on verbal aggressiveness, the $2^{\text {nd }}$ grade of secondary school the higher score on ego-orientation, the $1^{\text {st }}$ grade of secondary school the higher score on external reasons of discipline and the $5^{\text {th }}$ grade of primary school the lower score on caring reasons.

Previous study's findings argued that instructors' personality plays a determinant role in the interrelationship with their students (Rancer \& Avtgis, 2014). In this specific case, students' personal orientations and discipline reasons were influenced by instructors' verbal aggressiveness. Instructors' verbal aggressiveness emerged as the most important negative predictor of students' task-orientation and intrinsic reasons for discipline. This is in accordance with previous findings which suggested that teachers' verbal aggressiveness is negatively related with physical education students' intrinsic motivation and satisfaction (Bekiari, 2012, 2014; Kassing \& Infante, 1999). Similarly, the findings of a previous study argued that instructors' verbal aggressiveness has a negative effect on the students' satisfaction, intrinsic motivation and discipline factors related to intrinsic and caring reasons (Bekiari, Kokaridas, \& Sakellariou, 2006). A reasonable explanation of this finding could be the fact that task-orientated and internal disciplined students prefer to receive positive and encouraging feedback from their instructors (Sinclair \& Vealey, 1989; Smith \& Smoll, 1990).In any case, instructors’ verbal aggressiveness could be perceived by students as negative reinforcement, reporting also lower levels of intrinsic motivation, task orientation and increased stress levels (Digelidis \& Papaioannou, 1999).

Moreover, previous studies suggested that learning takes place in a well-organized and peaceful atmosphere (Good \& Grouws, 1977; Evertson, Anderson, Anderson, \& Brophy, 1980) as most physical education instructors believe that a well-disciplined class is one of the most important indices of successful teaching (Placek, 1983; Placer \& Dodds, 1988). It seems that instructors' verbal aggressiveness guides students to discipline. However, students' discipline due to verbal aggressiveness is negatively associated with students' intrinsic reasons and caring reasons for discipline in the classroom. It could be said that the distinctions between students' discipline which leads to an organized and peaceful atmosphere and instructors' verbal aggressiveness as a form of discipline are not yet clear. It is obvious that verbal aggressiveness is a demotivating force in the classroom (Gorham \& Christophel, 1992) leading the students to the forced discipline, negatively affecting their behavior,task orientation, intrinsic motivation, learningenvironment and satisfaction (Bekiari, 2014; Bekiari \& Syrmpas, 2015; Bekiari, Kokaridas, \& Sakellariou, 2006; Myers \& Knox, 1999; Myers \& Rocca, 2000; Myers, 2002). The study indicates the negative outcomes associated with physical education instructors' verbal aggressiveness and it is consistent with the findings of other research (Bekiari et al., 2015; Bekiari \& Manoli, 2016; Bekiari \& Hasanagas, 2015; Infante \& Wigley, 1986; Infante \& Rancer, 1996; Syrmpas \& Bekiari, 2015).

Moreover, two types may be distinguished, according to the sources of discipline. The "obedient" is a student who is extensively disciplined due to a wide variety of discipline factors (external and internal ones as well as responsibility). Simultaneously, such a disciplined student is targeted for verbal aggressiveness by the instructors and oriented to learning (task). The emergence of the "obedient" type may attribute to the fact that a strongly disciplined student easily becomes a target of verbal aggressiveness due to his tolerance and no reaction. At the same time, he is so tolerable because he is really oriented to task and not just to obtain degrees and marks. These typology results seem to be complementary to the previous findings (Bekiari \& Hasanagas, 2015; Bekiari, Hasanagas, Theoharis, Kefalas, \& Vasilou, 2015; Bekiari \& Spyropoulou, 2016; Hasanagas \& Bekiari, 2015) which have also proposed a connection of interpersonal relationships and verbal aggressiveness measured as a structural phenomenon.

The "altruist" appears not to be very different. He feels also verbally assaulted by the instructors and patiently interested in learning. The slight different in the "altruist" type consists in the sources of discipline seem to be quite different, namely internal factors and caring others. Thus, the two types seem differ from each other regarding the sources of discipline and similar to each other regarding being targeted for verbal aggressiveness and dedication to learning.

Furthermore, the $2^{\text {nd }}$ grade of secondary school proved to have the lower score on verbal aggressiveness, as they have been passed in a mature stage and are more strongly concerned by future carrier interests and stimuli, the $2^{\text {nd }}$ grade of secondary school the higher score on ego-orientation, as they have started to discover their skills and subsequently are interested in being distinguished, the $1^{\text {st }}$ grade of secondary school the higher score on external reasons of discipline, as they still have not strongly adopted social-or institution-based behavioural patterns, and the $5^{\text {th }}$ grade of primary school the lower score on caring reasons, as they children at this age are still quite individualistic and not strongly-embedded in any organized milieu or value system and they have not internalized and behavioral pattern based on any concept of social accountability. 


\section{Conclusion}

The study results echo the view of Infante and Rancer (1996), that the effects of verbal aggression are destructive, confirming and reinforcing also a moral attitude which has recently been adopted in education for the need for development of verbal aggressiveness control techniques. However, due to the small number of the results of this study sample should be interpreted carefully. Furthermore, future studies on a larger sample should examine and verify the results of this research on the relations of instructors' verbal aggressiveness to students' personal orientations and discipline reasons in physical education.

\section{References}

Anderson, C. M., \& Martin, M. M. (1995). Why Employees Speak to Coworkers and Bosses: Motives, Gender, and Organizational Satisfaction. Journal of Business Communication, 32, 249-265. http://dx.doi.org/10.1177/002194369503200303

Bekiari, A., \& Hasanagas, N. (2015). Sociological Insights in the Education System: “Unlocking” the Power Relations. Thessaloniki: Christodoulidis. (In Greek)

Bekiari, A., \& Hasanagas, N. (2016). “Educating” in Physical Education. Theoretical Approaches and Practical Inquiries. Thessaloniki: Christodoulidis. (In Greek)

Bekiari, A. (2012). Perceptions of Instructors’ Verbal Aggressiveness and Physical Education Students’ Affective Learning. Perceptual and Motor Skills, 115, 325-335. http://dx.doi.org/10.2466/06.11.16.PMS.115.4.325-335

Bekiari, A. (2014). Verbal Aggressiveness and Leadership Style of Sport Instructors and Their Relationship with Athletes' Intrinsic Motivation. Creative Education, 5, 114-121. http://dx.doi.org/10.4236/ce.2014.52018

Bekiari, A., \& Digelidis, N. (2015). Measuring Verbal Aggressiveness in Sport and Education. International Journal of Physical Education, 4, 12-21.

Bekiari, A., \& Hasanagas, N. (2015). Verbal Aggressiveness Exploration through Complete Social Network Analysis: Using Physical Education Students' Class as an Illustration. International Journal of Social Science Studies, 3, 30-49. http://dx.doi.org/10.11114/ijsss.v3i3.729

Bekiari, A., \& Hasanagas, N. (2016). Suggesting Indicators of Superficiality and Purity in Verbal Aggressiveness. An Application in Adult Education Class Networks of Prisoners. Open Journal of Social Sciences, 4, 279-292. http://dx.doi.org/10.4236/jss.2016.43035

Bekiari, A., \& Sakellariou, K. (2002). Perceived Instructor Verbal Aggressiveness and Student State Learning in Physical Education. Italian Journal of Sport Sciences, 1, 251-256.

Bekiari, A., \& Spyropoulou, S. (2016). Exploration of Verbal Aggressiveness and Interpersonal Attraction through Social Network Analysis: Using University Physical Education Class as an Illustration. Open Journal of Social Sciences, 4, 145155. http://dx.doi.org/10.4236/jss.2016.46016

Bekiari, A., \& Syrmbas, I. (2015). The Influence of Motivational Climate and Coaches’ Verbal Aggression on Athletes’ Satisfaction. British Journal of Education, Society \& Behavioural Science, 9, 318-329. http://dx.doi.org/10.9734/BJESBS/2015/17757

Bekiari, A., \& Manoli, P. (2016). EFL Teacher Verbal Aggressiveness and Argumentativeness and Student Socio-Affective Strategy Use and Affective Learning: Exploring Possible Associations. Journal of Teacher Education and Educators, 5. (Forthcoming)

Bekiari, A., Kokaridas, D., \& Sakellariou, K. (2005). Verbal Aggressiveness of Physical Education Teachers and Students' Self-Reports of Behavior. Psychological Reports, 96, 493-498. http://dx.doi.org/10.2466/pr0.96.2.493-498

Bekiari, A., Kokaridas, D., \& Sakellariou, K. (2006). Associations of Students' Self-Report of Their Teacher's Verbal Aggression, Intrinsic Motivation, and Perceptions of Reasons for Discipline in Greek Physical Education Classes. Psychological Reports, 98, 451-461. http://dx.doi.org/10.2466/pr0.98.2.451-461

Bekiari, A., Koustelios, A., \& Sakellariou, K. (2000). Instructors’ Verbal Aggressiveness from Universities in Greece. Studi e Ricerche, 5/6, 225-232.

Bekiari, A., Patsiaouras, A., Kokaridas, D., \& Sakellariou, K. (2006). The Relationship between Verbal Aggressiveness and State Anxiety in Volleyball. Perceptual and Motor Skills, 99, 630-634.

Bekiari, A., Perkos, S., \& Gerodimos, V. (2015). Verbal Aggression in Basketball: Perceived Coach Use and Athlete Intrinsic and Extrinsic Motivation. Journal of Physical Education and Sport, 15, 96-102.

Bekiari, A., Hasanagas, N., Theoharis, D., Kefalas, I., \& Vasilou, A. (2015). The Role of Mathematical Object and the Educational Environment to Students' Interpersonal Relationships: An Application of Full Social Network Analysis. In 32nd Congress Greek Mathematical Society (pp. 799-812). 
Bredemeier, B. J., Weiss, M. R., Shields, D. L., \& Cooper, B. (1986). The Relationship of Sport Involvement with Children’s Moral Reasoning and Aggression Tendencies. Journal of Sport \& Exercise Psychology, 8, 304-318.

Butler, R., \& Shibaz, L. (2008). Achievement Goals for Teaching as Predictors of Students' Perceptions of Instructional Practices and Students' Help Seeking and Cheating. Learning and Instruction, 18, 453-467.

http://dx.doi.org/10.1016/j.learninstruc.2008.06.004

Claus, C. J., Chory, R. M., \& Malachowski, C. C. (2011). The Relationship between Instructor Aggressive Communication Traits and Student Antisocial Behavioural Alteration Techniques. In The Annual Meeting of the Eastern Communication Association.

Deci, E. L., \& Ryan, R. M. (1985a). Intrinsic Motivation and Self-Determination in Human Behavior. NewYork: Plenum. http://dx.doi.org/10.1007/978-1-4899-2271-7

Deci, E. L., \& Ryan, R. M. (1985b). The General Causality Orientations Scale: Self-Determination in Personality. Journal of Research in Personality, 19, 109-134. http://dx.doi.org/10.1016/0092-6566(85)90023-6

Digelidis, N., \& Papaioannou, A. (1999). Age-Group Differences in Intrinsic Motivation, Goal Orientations and Perceptions of Athletic Competence, Physical Appearance and Motivational Climate in Greek Physical Education. Scandinavian Journal of Medicine \& Science in Sports, 9, 375-380. http://dx.doi.org/10.1111/j.1600-0838.1999.tb00259.x

Duda, J. L. (1989). Relationship between Task and Ego Orientation and the Perceived Purpose of Sport among High School Athletes. Journal of Sport \& Exercise Psychology, 11, 318-335.

Duda, J. L., \& Nicholls, J. G. (1992). Dimensions of Achievement Motivation in Schoolwork and Sport. Journal of Educational Psychology, 84, 290-299. http://dx.doi.org/10.1037/0022-0663.84.3.290

Dweck, C. S., \& Leggett, E. L. (1988). A Social-Cognitive Approach to Motivation and Personality. Psychological Review, 95, 256-273. http://dx.doi.org/10.1037/0033-295X.95.2.256

Edwards, C., \& Myers, S. A. (2007). Perceived Instructor Credibility as a Function of Instructor Aggressive Communication. Communication Research Reports, 24, 47-53. http://dx.doi.org/10.1080/08824090601128141

Evertson, C. M., Anderson, C. W., Anderson, L. M., \& Brophy, J. E. (1980). Relationships between Classroom Behaviors and Student Outcomes in Junior High Mathematics and English Classes. American Educational Research Journal, 17, 4360. http://dx.doi.org/10.3102/00028312017001043

Fox, K., Goudas, M., Biddle, S., Duda, J., \& Armstrong, N. (1994). Children’s Task and Ego Goal Profiles in Sport. British Journal of Educational Psychology, 64, 253-261. http://dx.doi.org/10.1111/j.2044-8279.1994.tb01100.x

Giannoudis, G., Digelidis, N., \& Papaioannou, A. (2009). The Motivation Climate and Perceived Sport Teachers’ Behavior toward Disciplined-Undisciplined Students. Inquiries in Sport \& Physical Education, 7, 10-21.

Good, T. L., \& Grouws, D. A. (1977). Teaching Effects: A Process-Product Study in Fourth Grade Mathematics Classrooms. Journal of Teacher Education, 28, 49-54. http://dx.doi.org/10.1177/002248717702800310

Gorham, J., \& Christophel, D. M. (1992). Students' Perceptions of Teacher Behaviors as Motivating and Demotivating Factors in College Classes. Communication Quarterly, 40, 239-252. http://dx.doi.org/10.1080/01463379209369839

Gråstén, A., Jaakkola, T., Liukkonen, J., Watt, A., \& Yli-Piipari, S. (2012). Prediction of Enjoyment in School Physical Education. Journal of Sports Science \& Medicine, 11, 260-269.

Hasanagas, N., \& Bekiari, A. (2015). Depicting Determinants and Effects of Intimacy and Verbal Aggressiveness Target through Social Network Analysis. Sociology Mind, 5, 162-175. http://dx.doi.org/10.4236/sm.2015.53015

Hassandra, M., Bekiari, A., \& Sakellariou, K. (2007). Physical Education Teacher’s Verbal Aggression and Student’s Fair Play Behaviors. The Physical Educator, 64, 94-101.

Hellison, D. R. (1985). Goals and Strategies for Teaching Physical Education. Champaign, IL: Human Kinetics Publishers, Inc.

Huang, D. B., Cherek, D. R., \& Lane, S. D. (1999). Laboratory Measurement of Aggression in High School Age Athletes: Provocation in a Nonsporting Context. Psychological Reports, 85, 1251-1262. http://dx.doi.org/10.2466/pr0.1999.85.3f.1251

Infante, D. A., \& Rancer, A. S. (1996). Argumentativeness and Verbal Aggressiveness: A Review of Recent Theory and Research. Communication Yearbook, 19, 319-352.

Infante, D. A., \& Wigley III, C. J. (1986). Verbal Aggressiveness: An Interpersonal Model and Measure. Communication Monographs, 53, 61-69. http://dx.doi.org/10.1080/03637758609376126

Infante, D. A., Myers, S. A., \& Buerkel, R. A. (1994). Argument and Verbal Aggression in Constructive and Destructive Family and Organizational Disagreements. Western Journal of Communication (Includes Communication Reports), 58, 73-84. http://dx.doi.org/10.1080/10570319409374488

Kokaridas, D., Bekiari, A., \& Sakellariou, K. (2005). Students’ Goal Orientations, Perceived Motivation Climate and Their 
Relation with the Selection of a Specialty. Journal of Human Movement Studies, 48, 181-194.

Lemieux, P., McKelvie, S. J., \& Stout, D. (2002). Self-Reported Hostile Aggression in Contact Athletes, No Contact Athletes and Non-Athletes. Athletic Insight, 4, 42-56.

Li, F., Harmer, P., Duncan, T. E., Duncan, S. C., Acock, A., \& Yamamoto, T. (1998). Confirmatory Factor Analysis of the Task and Ego Orientation in Sport Questionnaire with Cross-Validation. Research Quarterly for Exercise and Sport, 69, 276-283. http://dx.doi.org/10.1080/02701367.1998.10607694

Linnenbrink, E. A., \& Pintrich, P. R. (2002). Achievement Goal Theory and Affect: An Asymmetrical Bidirectional Model. Educational Psychologist, 37, 69-78. http://dx.doi.org/10.1207/S15326985EP3702_2

Manoli, P., \& Bekiari, A. (2015). EFL Teachers’ Verbal Aggressiveness and Students’ Intrinsic Motivation and SocialAffective Strategy Use: Investigating Possible Relations. Advances in Research, 5, 1-13. http://dx.doi.org/10.9734/AIR/2015/19692

Martin, M. M., Weber, K., \& Burant, P. A. (1997). Students’ Perceptions of a Teacher’s Use of Slang and Verbal Aggressiveness in a Lecture: An Experiment.

Mazer, J. P., \& Stowe, S. A. (2016). Can Teacher Immediacy Reduce the Impact of Verbal Aggressiveness? Examining Effects on Student Outcomes and Perceptions of Teacher Credibility. Western Journal of Communication, 80, 21-37. http://dx.doi.org/10.1080/10570314.2014.943421

Mazer, J. P., Barnes, K., Grevious, A., \& Boger, C. (2013). Coach Verbal Aggression: A Case Study Examining Effects on Athlete Motivation and Perceptions of Coach Credibility. International Journal of Sport Communication, 6, 203-213.

Myers, S. A., \& Knox, R. L. (1999). Verbal Aggression in the College Classroom: Perceived Instructor Use and Student Affective Learning. Communication Quarterly, 47, 33-45. http://dx.doi.org/10.1080/01463379909370122

Myers, S. A., \& Rocca, K. A. (2001). Perceived Instructor Argumentativeness and Verbal Aggressiveness in the College Classroom: Effects on Student Perceptions of Climate, Apprehension, and State Motivation. Western Journal of Communication (Includes Communication Reports), 65, 113-137. http://dx.doi.org/10.1080/10570310109374696

Myers, S. A., Edwards, C., Wahl, S. T., \& Martin, M. M. (2007). The Relationship between Perceived Instructor Aggressive Communication and College Student Involvement. Communication Education, 56, 495-508. http://dx.doi.org/10.1080/03634520701466398

Nicholls, J. (1984). Achievement Motivation: Conceptions of Ability, Subjective Experience, Task Choice, and Performance. Psychological Review, 91, 328-346. http://dx.doi.org/10.1037/0033-295X.91.3.328

Nicholls, J. (1989). The Competitive Ethos and Democratic Education. Cambridge, MA: Harvard University Press.

Papaioannou, A. (1998). Goal Perspectives, Reasons for Being Disciplined and Self-Reported Discipline in the Lesson of Physical Education. Journal of Teaching in Physical Education, 17, 421-441.

Papaioannou, A., \& Macdonald, A. I. (1993). Goal Perspectives and Purposes of Physical Education as Perceived by Greek Adolescents. Physical Education Review, 16, 41-48.

Placer, J. H., \& Dodds, P. (1988). A Critical Incident Study of Preservice Teachers’ Beliefs about Teaching Success and Nonsuccess. Research Quarterly for Exercise and Sport, 59, 351-358. http://dx.doi.org/10.1080/02701367.1988.10609382

Rancer, A. S., \& Avtgis, T. A. (2014). Argumentative and Aggressive Communication (2nd ed.). New York: Peter Lang.

Richmond, V. P., \& Gorham, J. (1992). Communication, Learning, and Affect in Instruction. Burgess International Group.

Rocca, K. A., \& McCroskey, J. C. (1999). The Interrelationship of Student Ratings of Instructors’ Immediacy, Verbal Aggressiveness, Homophily, and Interpersonal Attraction. Communication Education, 48, 308-316. http://dx.doi.org/10.1080/03634529909379181

Schrodt, P. (2003). Students' Appraisals of Instructors as a Function of Students' Perceptions of Instructors' Aggressive Communication. Communication Education, 52, 106-121. http://dx.doi.org/10.1080/03634520302468

Shim, S. S., Cho, Y., \& Cassady, J. (2013). Goal Structures: The Role of Teachers' Achievement Goals and Theories of Intelligence. The Journal of Experimental Education, 81, 84-104. http://dx.doi.org/10.1080/00220973.2011.635168

Smith, A. L., Balaguer, I., \& Duda, J. L. (2006). Goal Orientation Profile Differences on Perceived Motivational Climate, Perceived Peer Relationships, and Motivation-Related Responses of Youth Athletes. Journal of Sports Sciences, 24, 13151327. http://dx.doi.org/10.1080/02640410500520427

Syrmpas, I., \& Bekiari, A. (2015). The Relationship between Perceived Physical Education Teacher’s Verbal Aggressiveness and Argumentativeness with Students' Interpersonal Attraction. Inquiries in Sport \& Physical Education, 13, 21-32.

Treasure, D. C., \& Roberts, G. C. (1995). Applications of Achievement Goal Theory to Physical Education: Implications for Enhancing Motivation. Quest, 47, 475-489. http://dx.doi.org/10.1080/00336297.1995.10484170

Vallerand, R. J., Brière, N. M., Blanchard, C., \& Provencher, P. (1997). Development and Validation of the Multidimensional Sportspersonship Orientations Scale. Journal of Sport \& Exercise Psychology, 19, 197-206. 
Wang, C. J., Biddle, S. J., \& Elliot, A. J. (2007). The $2 \times 2$ Achievement Goal Framework in a Physical Education Context. Psychology of Sport and Exercise, 8, 147-168. http://dx.doi.org/10.1016/j.psychsport.2005.08.012

Williams, L., \& Gill, D. L. (1995). The Role of Perceived Competence in the Motivation of Physical Activity. Journal of Sport \& Exercise Psychology, 17, 363-378.

Wrench, J. S., \& Richmond, V. P. (2004). Understanding the Psychometric Properties of the Humor Assessment Instrument through an Analysis of the Relationships between Teacher Humor Assessment and Instructional Communication Variables in the College Classroom. Communication Research Reports, 21, 92-103. http://dx.doi.org/10.1080/08824090409359971

Yli-Piipari, S., Barkoukis, V., Jaakkola, T., \& Liukkonen, J. (2013). The Effect of Physical Education Goal Orientations and Enjoyment in Adolescent Physical Activity: A Parallel Process Latent Growth Analysis. Sport, Exercise, and Performance Psychology, 2, 15-31. http://dx.doi.org/10.1037/a0029806

\section{Submit or recommend next manuscript to SCIRP and we will provide best service for you:}

Accepting pre-submission inquiries through Email, Facebook, LinkedIn, Twitter, etc.

A wide selection of journals (inclusive of 9 subjects, more than 200 journals)

Providing 24-hour high-quality service

User-friendly online submission system

Fair and swift peer-review system

Efficient typesetting and proofreading procedure

Display of the result of downloads and visits, as well as the number of cited articles

Maximum dissemination of your research work

Submit your manuscript at: http://papersubmission.scirp.org/ 